\title{
ENTRE EL RECUERDO Y LA REIVINDICACIÓN: APOTEOSIS, EL ÁLBUM CONMEMORATIVO DE LA INAUGURACIÓN DEL PANTEÓN NACIONAL DE LOS HÉROES
}

\author{
Between memory and claim: Apotheosis, The memorial album of the \\ inauguration of the National Pantheon of the Heroes
}

\section{Herib Caballero Campos*}

\section{Resumen}

Este artículo estudia la forma de registro de la Reivindicación de la figura del mariscal Francisco Solano López como Héroe a través de una producción bibliográfica. Este nuevo enfoque triunfaba contra la hegemónica idea de que él era un tirano y por cuya voluntad el Paraguay ingresó a la Guerra de la Triple Alianza. En el trabajo se analiza el discurso y el tipo de documentos que componen el Álbum Apoteosis, en el cual se registra la culminación del traslado de los restos mortales de López desde el campo de Cerro Corá hasta el -recién inaugurado- Panteón Nacional de los Héroes. Para el desarrollo del trabajo se ha hecho un análisis de dicho Álbum que hoy en día constituye una verdadera rareza bibliográfica pues quedan muy pocos ejemplares. Además se ha completado la investigación con la revisión de documentos oficiales y testimonios de testigos. Este artículo contribuye a analizar uno de los principales registros emitidos por el gobierno del coronel Rafael Franco en su faceta reivindicatoria de la figura de Francisco Solano López.

$$
<\text { Héroes }><\text { Reivindicación }><\text { Lopizmo }><\text { Nacionalismo }><\text { Paraguay }>
$$

\begin{abstract}
This article examines how was recorded the figure of marshal Francisco Solano Lopez claimed as National Hero through a specific bibliographic production. This new approach triumphed against the hegemonic idea that he was a tyrant by whose will the Paraguay entered at the Triple Alliance War. This work analyses speeches and documents making up the Apotheosis Album. This album recorded the transfer of Lopez' remains from the Cerro Cora field to the National Pantheon of the Heroes. This work analyses that album which is a true rarity material with very few copies remaining. The investigation also considers official documents and testimonies of witnesses. This paper contributes to analyze one of the major records issued by the government of colonel Rafael Franco in his claim of the figure of Francisco Solano Lopez.
\end{abstract}

$$
<\text { Heroes }><\text { Claim }><\text { Lopizmo }><\text { Nationalism }><\text { Paraguay }>
$$

Recibido: 12/09/2015 // Aceptado: 13/11/2015

\footnotetext{
* Universidad Nacional de Asunción y CONACYT, caballerocamposherib@gmail.com
} 
Caballero Campos. Entre el recuerdo y la reivindicación: Apoteosis, el Álbum conmemorativo de la inauguración...

\section{Introducción}

El recientemente fallecido historiador francés, Jacques Le Goff afirma que la memoria colectiva es “...un instrumento y una mira de poder” (Le Goff, 1991: 181); en ese sentido este artículo se centra en el cierre de un ciclo para algunos o el inicio de otro, en el proceso de la memoria sobre la figura histórica del mariscal Francisco Solano López (1827-1870).

Juan Stefanich fue uno de los principales impulsores de la consagración como héroe de la figura de Francisco Solano López por parte del gobierno del coronel Rafael Franco (1936-1937); dicha reivindicación constituyó el fin de la polémica que habían animado en 1902 por un lado, Cecilio Báez y por el otro, Juan E. O’Leary sobre la heroicidad de Francisco Solano López. Al respecto de dicha polémica, la historiadora Liliana Brezzo considera que la misma fue una "controversia historiográfica inigualada" y que las "consecuencias han sido tan rotundas que llegan hasta el presente" (Brezzo, 2009).

En 1936 con la introducción de los restos de Francisco Solano López al entonces recientemente inaugurado Panteón de los Héroes, se realizó su apoteosis. Apoteosis es una palabra griega que significa contarse entre los dioses, divinizar, deificar; apo: idea de intensidad, theo: Dios, osis: formación, impulsión. En el diccionario se define a apoteosis como una ceremonia que hacían los antiguos para colocar en el número de los dioses o héroes a los emperadores, emperatrices u otros mortales. Según el Diccionario de la Real Academia Española, la palabra apoteosis deriva del latín apotheōsis, y este a su vez del gr. $\alpha \pi \circ \theta \varepsilon \dot{\varepsilon} \omega \sigma i \varsigma$, deificación. Su primera significación es la de ensalzamiento de una persona con grandes honores o alabanzas;tiene en total cuatro acepciones. ${ }^{1}$

La tarea emprendida por los partidarios de la reivindicación de la figura heroica de Francisco Solano López fue ardua pero constante, a lo largo de más de treinta años. En primer término, el centro estudiantil logró erigir un monumento a los Héroes de la Guerra, siendo una forma de instalar que todos los que pelearon dicha guerra eran héroes (Caballero Campos, 2012), y posteriormente se generó una discusión en el propio congreso paraguayo sobre la anulación de los decretos de proscripción que fueron dictados en 1869 (Archivo del Liberalismo, 1988), para lograr en 1931 que el 1 de marzo sea declarado feriado como Día de los Defensores de la Patria² (Caballero Campos, 2013).

Pero el paso más decidido fue el que dieron los integrantes del gabinete revolucionario constituido en febrero de 1936. Pocos días después del triunfo de dicho movimiento en una alocución radial el Presidente de la República, coronel Rafael Franco afirmó que:

\footnotetext{
1 Las otras acepciones son 2. f. Escena espectacular con que concluyen algunas funciones teatrales, normalmente de géneros ligeros.3. f. Manifestación de gran entusiasmo en algún momento de una celebración o acto colectivo.4. f. En el mundo clásico, concesión de la dignidad de dioses a los héroes.

2 El 1 de marzo de 1870 se libró la batalla de Cerro Corá, la última de la guerra contra la triple Alianza (Brasil, Argentina y Uruguay), en la cual fueron destruidos los restos del último ejército paraguayo y fue muerto el mariscal Francisco Solano López.
} 
"La figura del gran estadista que el pueblo paraguayo aclama en estos momentos y que el Gobierno Provisional honra con un decreto extraordinario, no es por cierto la que alguna vez fue presentada como el arquetipo de la arbitrariedad y la violencia (...) (el mariscal presidente) la figura histórica más alta y más completa que ha producido la Nación Paraguaya y es nuestro deber honrar su memoria esclarecida tanto como seguir su ejemplo" (El Diario, 1936).

Es indudable la impronta que caracterizaría al entonces recién asumido gobierno de Rafael Franco. En ese sentido, era clara la influencia política e intelectual de Juan Stefanich, quien ocupaba el cargo de ministro de Relaciones Exteriores e interino del ministerio de Defensa Nacional. Stefanich egresado del Colegio Nacional y de la Facultad de Derecho y Ciencias Sociales de la Universidad Nacional de Asunción, fue uno de los impulsores de una vertiente nacionalista que se aglutinó en torno a la Liga Nacional Independiente. Stefanich, al igual que los otros líderes nacionalistas, reconocía la impronta de Juan E. O’Leary a quien definía como “....abanderado mayor de la tierra paraguaya, reconstructor de la patria vieja, profesor insuperable de energía y de patriotismo" (Stefanich, 1929).

En este contexto el presente artículo pretende analizar el Álbum Apoteosis, que fue confeccionado por la Compañía Editorial $\mathrm{Nacional}^{3} \mathrm{y}$ financiado en parte por el gobierno revolucionario. Dicho álbum es un testimonio y a la vez una justificación de cuando se realizó la "apoteosis" de Francisco Solano López “durante el traslado de 'sus' ‘cenizas’ al Panteón Nacional el 12 de octubre” (Capdevila, 2010: 220).

\section{La discusión sobre la heroicidad de López}

En este apartado quisiéramos referirnos a los tres momentos de la discusión en torno a la figura de Francisco Solano López que se inició ya en el transcurso del mismo conflicto. En este sentido podemos afirmar que los momentos son los siguientes:

\section{Denigrativo (1869-1902)}

\section{Reivindicativo (1902-1936)}

\section{Consagratorio (1936-1989)}

El primer momento fue el Denigrativo, que comienza con la promulgación del decreto del gobierno provisorio compuesto por Cirilo A. Rivarola, Carlos Loizaga y José Díaz de Bedoya, que entró en funciones el 15 de agosto de 1869 con el beneplácito de las tropas aliadas de ocupación y cuando aún la guerra no había concluido.

Entre las primeras medidas de dicho gobierno se encuentra el decreto fechado el 17 de agosto de 1869, por el cual establecían en el primer artículo que el desnaturalizado

\footnotetext{
3 La Compañía Editora Nacional fue fundada y dirigida por Leopoldo Ramos Giménez, y la misma fue sustituida por la Compañía Editorial Paraguaya, fundada en 1940.
} 
paraguayo Francisco Solano López, queda fuera de la ley y para siempre arrojado del suelo paraguayo como asesino de su patria y enemigo del género humano.

En el manifiesto al pueblo paraguayo dictado por el mencionado gobierno provisorio, en fecha 10 de septiembre de 1869, se afirmaba entre otras cuestiones que:

"La tiranía del país, ya en su agonía, escupe todavía a la faz de la civilización, devolviéndole en la condición más mísera y abyecta, los restos truncados del heroico pueblo, cuyo valor virtud y abnegación merecen el respeto universal", y para aclarar aún más se preguntaba “¿Puede inculparse al pueblo paraguayo de todos estos crímenes? No [...] la víctima jamás fue cómplice del verdugo" (La Regeneración, 1869).

Casi dos años después de la emisión del decreto de proscripción y concluida la guerra, el Congreso Paraguayo sancionó una ley de la nación que aprobaba el decreto del 17 de agosto de 1869 por el cual se declara "al desnaturalizado Francisco Solano López fuera de la ley". En el segundo artículo se dispone que los integrantes de la familia López Carrillo "han sido cómplices y herederos de los robos y dilapidaciones hechas por los gobiernos de los López, queda autorizado el poder judicial a trabar embargo de los bienes adquiridos desde el primer día del gobierno de Carlos A. López..." (Registro Oficial, 1871: 229).

Durante este período la figura de Francisco Solano López está prácticamente ausente de los periódicos. Las pocas veces que se hace mención a su persona se refieren a él como tirano. Dicha situación cambiaría paulatinamente cuando en la década de 1890 comenzó la campaña en la búsqueda de un héroe que personifique a los que habían caído en defensa de la patria. Es así que Juan Silvano Godoi y otros desempolvaron la figura del general José Eduvigis Díaz, y empezaron la campaña por el reconocimiento de Díaz como el gran héroe nacional (Caballero Campos, 2014).

Esta etapa se inicia con la labor de Blas Garay, quien publicó su breve Historia del Paraguay en Madrid en 1895. En ella intenta construir un discurso histórico de carácter más científico, que supera la tendencia de menoscabar la figura de Francisco Solano López. Esta posición rompía con la predisposición instalada que era antilopizta, pues como sostiene Tomás Sansón los que cultivaron la historia en este período "Implementaron una política oficial de elisión y demonización del Mariscal, inaugurada con la ley de "desnaturalización" del 13 de julio de 1871, que tuvo su correlato historiográfico en una interpretación que pugnó por transformarse en hegemónica" (Sansón, 2012).

El segundo momento o Reivindicatorio se desarrolla a partir de la tarea de un joven estudiante, Juan E. O'Leary, quien se enfrentó a Cecilio Báez -el más importante intelectual paraguayo de la época- en una polémica que tuvo casi cuatro meses de duración en la que se discutió sobre la heroicidad de Francisco Solano López, 
y como telón de fondo, toda la guerra. Según la historiadora argentina Liliana Brezzo, el discurso de O'Leary se movía entre dos coordenadas "la conversión de las derrotas en glorias nacionales y la idealización del pasado para superar un presente adverso"; al lograr superar a su contrincante en la polémica, logró realizar indudablemente "la apoteosis del vencido, una representación en la que la realidad e invención quedaban tan magistralmente imbricadas" (Brezzo, 2011: 54-55).

A partir del triunfo de O'Leary en esta polémica, su figura fue in crescendo entre la juventud que lo veía no sólo como un paladín de la reivindicación sino de la propia nación paraguaya. O'Leary utilizó todas las herramientas a su alcance para lograr su objetivo: la prensa, la cátedra ${ }^{4}$, las conferencias y las publicaciones bibliográficas. El discurso histórico de O'Leary “....irá desenvolviéndose en los años siguientes [...] por la acción político cultural de O'Leary en el contexto de los gobiernos liberales, más en oposición al liberalismo" (Brezzo, 2011: 103).

Tal fue la impronta de O'Leary que años después el entonces joven Juan Stefanich, dirigente del centro estudiantil -en el cual se encontraban agremiados los estudiantes del Colegio Nacional de Asunción- recordaba sobre el mariscal Francisco Solano López "...este nombre inspira horror y aversión a muchas personas. También nosotros aprendimos a odiarle desde niños" (Stefanich, 1920: 162).

Fueron durante este período que se fueron organizando distintos núcleos nacionalistas, inspirados por O'Leary; integrados en su mayoría por jóvenes que pertenecían a los dos partidos tradicionales o incluso no tenían ninguna adscripción política.

El primer desafío fue el de erigir un monumento a los héroes de la guerra por diversos motivos. La idea tardó en ser concretada; durante más de una década se hicieron trámites, se recolectaron contribuciones en todos los pueblos para dicho monumento, finalmente inaugurado el 1 de marzo de 1922 (Caballero Campos, 2012). La inauguración realizada el 1 de marzo y no el 25 de noviembre-Día de la Constitución Liberal- fue un tácito triunfo de los reivindicadores de la figura de Solano López. Dos años antes, una numerosa manifestación recordó el cincuentenario de la batalla de Cerro Corá. El orador principal fue el joven dirigente nacionalista, Juan Natalicio González.

En 1926 se dio el siguiente hito en la campaña reivindicatoria, cuando tres diputados propusieron derogar el decreto del 17 de agosto de 1869 así como la ley del 7 de agosto de 1871, por considerar que esta era el resultado de un gobierno espurio, pues "el gobierno provisorio de 1869-1870 creado por la Triple Alianza, tenía que obedecer en consecuencia a los mandatos que emanaban de ella" (Archivo del Liberalismo, 1988: 11).

En 1931, en la nueva ley de feriados, los lopistas lograron el establecimiento del 1 de marzo como feriado con la advocación de Día de los Defensores de la Patria,

\footnotetext{
${ }_{4}$ En 1900, Juan E O'Leary fue designado como profesor de historia americana y nacional en el Colegio Nacional de Asunción (Brezzo, 2011: 35).
} 
Caballero Campos. Entre el recuerdo y la reivindicación: Apoteosis, el Álbum conmemorativo de la inauguración...

lo cual era un reconocimiento al rol que también tuvo Solano López, desde la óptica reivindicativa nacionalista.

Al año siguiente, en 1932 estalló la Guerra del Chaco contra Bolivia, la que duraría hasta 1935. Durante los años de la guerra, O’Leary fue invitado a dar conferencias en las diversas poblaciones del Paraguay con el objetivo de infundir el patriotismo a la población recordando las glorias nacionales de la pasada guerra. En ese marco el nacionalismo logró el medio de comunicación necesario para extenderse en cada rincón del Paraguay.

Ocho meses después de concluir la Guerra del Chaco, se produjo un movimiento revolucionario que depuso al presidente Eusebio Ayala (1932-1936) y al régimen liberal que imperaba en el país; las fuerzas aglutinadas en el movimiento de febrero tenían por denominador común su antiliberalismo y su nacionalismo. Es así que desde 1936 se produce el inicio del momento Consagratorio que provisoriamente colocamos su duración hasta 1989. El gobierno febrerista encabezado por Rafael Franco (1936-1937), según Erasmo González, tomó como "bandera el nacionalismo, se escucharon discursos contra los que atentaron contra lo paraguayo, por ello fue necesaria la creación de una nueva historia para descubrir que las figuras del pasado fueron héroes de la patria" (González, 2011: 123-124). Con el traslado de las cenizas de Francisco Solano López al entonces recientemente inaugurado panteón nacional de los héroes junto a los restos del soldado desconocido del Chaco, se logró su apoteosis como veremos más adelante. Es indudable que "desde el Centenario y hasta mediados del siglo XX, el nacionalismo impregnó toda la explicación sobre el pasado paraguayo" (Brezzo, 2010: 234) y por lo tanto el nacionalismo logró establecerse como "el substrato del imaginario nacional sobre el cual se cristalizaron las identidades colectivas, desde la izquierda comunista hasta los nacionalistas fascistas del partido Colorado" (Capdevila, 2010: 120).

El gobierno del general Higinio Morínigo (1940-1948) afirmaba que él mismo estaba conduciendo la Revolución Nacionalista o en algunos otros documentos que era la Revolución Paraguaya la que estaba conduciendo su gobierno (Gómez Florentín, 2011). Los años siguientes fueron de acrecentamiento de la reivindicación de la figura de Francisco Solano López como héroe máximo de la nacionalidad. Se realizó como un culto cívico ineludible durante el largo régimen dictatorial del general Alfredo Stroessner (1954-1989), quien incluso por un decreto del 16 de septiembre de 1964 dispuso que el Día del Ejército Paraguayo sea recordado cada 24 de julio, en homenaje al natalicio de Francisco Solano López.

Según la investigadora Gaya Makaran “el stronismo se formó de los elementos ya presentes, pero dispersos en el imaginario nacionalista paraguayo, permeó a la sociedad entera al grado que ésta asumió la propaganda oficial, como creencias íntimas. Los largos años del nacionalismo autoritario, plasmados en la educación y las ceremonias públicas, afectaron la conciencia crítica de la sociedad y generalizaron como "natural" el modo oficialista y colorado de ser y pensarse como paraguayo" (Makaran, 2014: 97).

El sociólogo Roberto Céspedes Ruffinelli al estudiar la iconografía en los billetes emitidos durante el régimen stronista afirma que de los mismos se pueden 
visualizar "tres ejes en el discurso: el maniqueísmo, el héroe máximo y la edad de oro", lo que permite distinguir entre los buenos y malos paraguayos, en el cual se destaca al mariscal Francisco Solano López como el héroe máximo del Paraguay. Se establece la edad de oro de la historia del Paraguay entre los gobiernos de José Gaspar Rodríguez de Francia y Carlos Antonio López (Céspedes Ruffinelli, 2014).

\section{El comienzo de la consagración}

El 17 de febrero de 1936 un grupo de oficiales acantonados en el cuartel de Campo Grande, ubicado a 9 kilómetros del centro de la capital paraguaya, se movilizaron para derrocar al gobierno del liberal Eusebio Ayala (1932-1936). Según Javier Mendiguren "la insurrección armada, iniciada por los veteranos de la Guerra del Chaco, conjuntamente con la oficialidad joven del ejército, sumados a los grupos civiles, casi todos ellos universitarios, estudiantes e intelectuales, era la consecuencia lógica de descontentos y rebeldías generalizados que dejaba como saldo la contienda bélica con Bolivia, recientemente finalizada" (Mendiguren -Sorázabal, 2001: 11).

En el decreto plesbicitario del ejército libertador -como se autodenominaron los revolucionarios- se puede observar ya el carácter nacionalista y reivindicatorio cuando se dirigían "¡PARAGUAYOS! ¡PUEBLO ILUSTRE DE ANTEQUERA, RODRÍGUEZ DE FRANCIA Y DE LOS LÓPEZ!'”; en el discurso explicaban los motivos de la acción que habían llevado adelante y los motivos de la destitución del presidente de la república Eusebio Ayala, en líneas generales el mencionado documento "carecía totalmente de bases programáticas que animen el movimiento" (Arce Farina, 2013: 39).

El coronel Rafael Franco, quien se encontraba exiliado en la ciudad de Buenos Aires desde fines de enero de 1936, arribó al país el 20 de febrero para asumir la presidencia de la república en carácter provisional. Al llegar al país formuló declaraciones sobre las bases que sostendrían su gobierno y afirmó que "La obra renovadora de la revolución se asienta sobre el respeto de los valores auténticos de nuestra Nación" y para que no quede duda aclaró "Nacionalistas en el más alto y en el más amplio de los sentidos, todas las virtudes de nuestro pueblo, su genio, su espíritu y sus vocaciones fundamentales encontrarán en nuestra propia acción el ambiente propicio que necesitan y la bandera nacional no será arriada en ningún lugar" (Arce Farina, 2013: 41).

El 1 de marzo de 1936, se organizó un acto público para honrar a los héroes de la guerra contra la Triple Alianza, y en particular al mariscal Francisco Solano López; por primera vez, afirmaba el presidente Rafael Franco, se daba la oportunidad de honrar a "la figura histórica más alta y más completa que ha producido la Nación Paraguaya y es nuestro deber honrar su memoria esclarecida tanto como seguir su ejemplo" (E1 Diario, 1936), por lo que se había dictado un decreto-ley que declaraba nulo el decreto del 17 de agosto de 1869 y las demás medidas legales vinculadas al mismo. En la segunda parte del Decreto se disponía que se erigiría en la colina más alta de la capital paraguaya un monumento para honrar la memoria "del ilustre gobernante que cayó en defensa de su Patria" (E1 Diario, 1936). 
El siguiente paso fue finalizar el oratorio a la Virgen de la Asunción que había sido construido por orden de Francisco Solano López antes de la guerra - con el fin de ser oratorio de la Virgen de la Asunción- y a consecuencia de ella quedó inconcluso. Afirmaba Stefanich que el oratorio "quedó en el centro de la ciudad como un sangrante muñón del pasado, destinado a sufrir las injurias del tiempo y de los hombres" (Stefanich, 1945: 12).

Una de las primeras obras del gobierno de Franco fue ordenar la conclusión del oratorio, por lo que "manos de artistas y artesanos pusiéronse a la obra ¿Cien obreros no fueron suficientes? Pusiéronse doscientos, aumentáronse hasta trescientos. ¿No bastaba el trabajo diurno? Se trabajó de noche. Y por primera vez aquella ciudad habituada al abandono y a la lentitud, contempló el espectáculo de una obra edilicia acelerada con el trabajo nocturno a la luz de las bujías eléctricas" (Stefanich, 1945: 14-15). El trabajo arduo dio resultados y la obra estuvo concluida para los primeros días del mes de septiembre 1936. El 14 de septiembre se dictó un decreto en cuyas consideraciones afirmaba que "el deber incumbe al pueblo y al gobierno de la república de tributar un homenaje digno y perdurable a la memoria de los próceres beneméritos de la patria que contribuyeron con sus sacrificios y sus esfuerzos a conquistarla libertad política de la nación y a darle fisonomía destacada en el concierto internacional" y además "la necesidad y conveniencia de consagrar a la memoria de quienes todo lo dieron por la felicidad y el bienestar de su pueblo el monumento histórico, inconcluso erigido en la capital de la República...". Por todo lo expuesto el decreto establecía que el monumento se denominaría Panteón Nacional en el cual se debían conservar "los restos de los próceres beneméritos de la nación, que se hicieron acreedores de la gratitud de la posteridad por sus virtudes excepcionales al servicio de la Patria" (Registro Oficial, 1936). El mencionado decreto establecía en su segundo artículo quiénes eran los próceres beneméritos, y los designados fueron los tres primeros gobernantes del Paraguay: José Gaspar Rodríguez de Francia, Carlos Antonio López y el mariscal Francisco Solano López. El siguiente artículo disponía que los restos del mariscal Francisco Solano López sean depositados en dicho panteón, y el artículo 4 establecía que sean trasladados los restos de tres jefes militares que "tuvieron actuación descollante en la defensa del territorio patrio en la guerra contra la triple alianza" (Registro Oficial, 1936). Así mismo disponía el gobierno el traslado de los restos de un soldado desconocido caído en la reciente Guerra del Chaco. El día fijado para la inauguración del Panteón Nacional fue el 12 de octubre, por ser ese día "día de la Raza y aniversario del Descubrimiento de América" (Registro Oficial, 1936).

Previamente, se había ya organizado la búsqueda de los restos de Francisco Solano, pues estaban enterrados en Cerro Corá. La tradición histórica afirmaba que fue enterrado junto con su hijo Panchito, quien también pereció en dicha batalla. Para encargarse de la búsqueda de los restos de Francisco Solano López, se constituyó una comisión especial en la ciudad de Concepción a los efectos de ubicarlos y trasladarlos hasta la capital. El presidente de la Comisión fue don Romualdo Yrygoyen (Stefanich, 1945:21). 
La comisión se encargó de recoger testimonios orales sobre la ubicación de la tumba y para ello el testimonio más veraz -y posiblemente uno de los pocos que se pudieron recoger por el tiempo transcurrido- fue el del veterano Bonifacio Obando, quien dio las indicaciones para la ubicación de la tumba, pues él había estado en el lugar en 1880 y había marcado un árbol de curupay cerca de donde se encontraba la tumba (Stefanich, 1945, 23).

El 28 de agosto de 1936 la comisión especial se trasladó hasta Cerro Corá y comenzó los trabajos de abrir una picada a los efectos de ubicar el árbol de curupay. Llegaron al lugar el 2 de septiembre de 1936 y procedieron a excavar en el lugar "se extrajeron algunos restos de madera, piedras mezcladas con tierra negra y colorada. $\mathrm{Y}$ a la profundidad de un metro encontraron algunos pocos y menudos fragmentos de huesos humanos que fueron cuidadosamente recogidos. Era todo lo que restaba en las dos tumbas. No había más" (Stefanich, 1945, 25).

Los restos fueron conducidos en una urna de madera hasta la ciudad de Concepción -ubicada sobre el río Paraguay-y desde allí en el cañonero Humaitá hasta la ciudad de Asunción, arribando a la capital paraguaya el 11 de octubre de 1936. La urna que contenía los restos extraídos del campo de Cerro Corá junto con la que contenía los restos del soldado desconocido del Chaco fueron conducidas hasta el Palacio de Gobierno en donde se instaló una capilla ardiente, por la cual pasaron miles de personas, durante toda la tarde y la noche. Uno de los hechos más significativos de aquella jornada y destacado por la prensa fue que un grupo de veteranos de la Guerra contra la Triple Alianza se mantuvieron en la capilla ardiente toda la noche.

El 12 de octubre bien temprano, una comitiva encabezada por el presidente Rafael Franco condujo en cureña las dos urnas hasta el Panteón Nacional, que de esa forma quedó inaugurado oficialmente aquel día.

Desde ese momento el Panteón Nacional se fue constituyendo en el punto simbólico de la sociedad paraguaya como resultado del nacionalismo que se volvió la ideología predominante del estado paraguayo durante los siguientes cincuenta años.

\section{El álbum Apoteosis}

En este apartado analizaremos el testimonio bibliográfico del proceso de reivindicación, búsqueda de los restos y finalmente la consagración de Francisco Solano López como la figura más encumbrada de la Historia Paraguaya. Dicho testimonio bibliográfico lo constituye el Álbum Apoteosis, que fue editado y dirigido por Leopoldo Ramos Giménez, quien a la sazón dirigía la Compañía Editora Nacional.

La propuesta original de Ramos Giménez al gobierno paraguayo fue que a cambio de una ayuda de 350.000 pesos, la editorial entregaría cien ejemplares a la Comisión Nacional de Inauguración del Panteón Nacional de los Héroes (Registro Oficial, 1936).

Por el Decreto ley número 5505, del 8 de octubre de 1936, se autorizó la edición del álbum Apoteosis, para lo cual se aceptó en el Consejo de Ministros la segunda 
propuesta presentada por la casa editorial que consistía en el aporte de 87.500 pesos por parte del gobierno a cambio de 25 ejemplares que serían entregados a la comisión antes mencionada.

El artículo 1 del citado decreto afirmaba "Autorízase la edición del Álbum "Apoteosis" propuesta por la Compañía Editora Nacional, en conmemoración de la inauguración del Panteón Nacional y del depósito en el mismo de los restos del Mariscal Presidente de la República, don Francisco Solano López y del soldado Paraguayo caído en el Chaco en la pasada guerra" (Registro Oficial, 1936, 1557).

El artículo $3^{\circ}$ establecía las características generales del Álbum, que debía ser de una dimensión de $0.57 \mathrm{mts}$ x 0,37 mts, encuadernada en tela, impreso en papel de lujo y con inscripciones en letras doradas (Registro Oficial, 1936, 1557).

El responsable de la edición fue Leopoldo Ramos Giménez, quien entonces se encontraba fungiendo de Secretario de la Delegación Paraguaya ante la Conferencia de Paz con Bolivia en la ciudad de Buenos Aires (Registro Oficial, 1936).

Leopoldo Ramos Giménez nació en Villarrica el 14 de octubre de 1891 y falleció en Asunción el 5 de enero de 1988. Ramos Giménez fue un precoz poeta y periodista, pues "comenzó a escribir en los periódicos de su ciudad natal. Después en 1914 envió algunas colaboraciones para Crónica" (Centurión, 1951,55). Pero no sólo se destacó como poeta, sino que también fue "orador de ademanes rotundos y espléndido verbo tribunicio". Entre sus obras se encuentran Piras Sagradas, 1917; Eros, 1918; Alas y Sombras, 1920; Cantos del Solar Heroico, 1920; entre otras. Creó y dirigió la Compañía Editora Nacional a la que siguió la Compañía Editorial Paraguaya (Centurión, 1951,58).

En su juventud fue un ferviente defensor de las causas obreras y por lo tanto adscribió al anarquismo, sin dejar de militar en las filas de la Asociación Nacional Republicana, Partido Colorado - uno de los partidos tradicionales-; ferviente nacionalista y lopista era un "apasionado de nuestra historia, no se detenía a medir la talla intelectual o la figuración política de algún eventual contendor, para esgrimir su pluma en justificación de nuestra historia. Así en defensa del mariscal López por la prensa de Río de Janeiro y Sao Paulo, o en defensa de los derechos del Paraguay sobre el Chaco mediante una ponderada cartografía con sus explicaciones correspondientes" (Benítez, 1986,319).

En una entrevista realizada por el historiador paraguayo Alfredo Seiferheld, Leopoldo Ramos Giménez respondía a la pregunta: ¿Ud. fue lopista siempre? "Desde chico, mi padre, imagínese, se indignaba tanto por la campaña legionaria que había después de la guerra que, naturalmente, ante la indignación de él, yo me sentía más indignado todavía como joven" (ABC Color, 1985).

Durante el régimen de Alfredo Stroessner ocupó por muchos años la función de subsecretario de informaciones y cultura de la Presidencia de la República.

Leopoldo Ramos Giménez fue el propulsor de la realización de dicho álbum con el fin de registrar la consagración de Solano López y el final de su reivindicación 
frente a su proscripción decretada al final de la Guerra contra la Triple Alianza por sus rivales políticos.

\section{El contenido del Álbum}

En cuanto al aspecto formal las dimensiones del álbum se aproximan a lo establecido en el decreto, pues tiene $54 \mathrm{~cm}$. de largo x $36 \mathrm{~cm}$. de ancho. La tapa está forrada en cuero de color azul y en letras doradas está el escudo de la república y la palabra apoteosis en mayúsculas.

Está compuesto por setenta páginas que no se encuentran numeradas y que fueron impresas en un papel de alto gramaje; las páginas en donde se encuentran ubicados los textos están con márgenes en dorado. Al dorso de cada hoja se encuentra como marca de agua la imagen de un soldado paraguayo del Chaco haciendo guardia, mensaje muy significativo pues lo que se deja entrever es que a la sombra del heroísmo de Francisco Solano López, los soldados paraguayos triunfaron en el Chaco. Siendo de esta forma como la revancha que se tomó el pueblo paraguayo en contra de la derrota en la Triple Alianza. En su discurso el canciller Stefanich afirmó "Es su compañero y está junto a él en la inmortalidad y en el austero recinto del Panteón Nacional, el Soldado insuperable del Chaco continuador de sus hazañas y salvador de la patria en la segunda epopeya" (Stefanich 1945, 61).

El encuadernado es sencillo y fue realizado con un cordón grueso de color púrpura. Así mismo se han colocado hojas protectoras frente a las principales ilustraciones.

A continuación de la portada, el álbum incluye una imagen del mariscal Francisco Solano López colocada en una cartulina de color gris que funge de paspartú; luego le sigue una fotografía del Presidente Provisional coronel Rafael Franco, afirmando que bajo su gobierno se ha hecho "la gran justicia histórica". Luego le sigue la reproducción del autógrafo del coronel Franco, en la siguiente página se encuentra la fotografía, un mensaje y el autógrafo del doctor Juan Stefanich.

En la siguiente página se encuentra transcripto íntegramente el decreto del 1 de marzo de 1936 bajo el acápite de TOTAL REPARACIÓN HISTÓRICA. Posteriormente se publica la relación escrita por Stefanich sobre la exhumación de los restos de López en Cerro Corá, incluyendo fotografías de la expedición encabezada por el señor Romualdo Yrygoyen. Posteriormente le sigue un artículo de Juan Stefanich sobre la memoria de los López en el significado del nacionalismo paraguayo, acompañado de la poesía del propio Ramos Giménez. La cumbre del Titán, uno de cuyos versos dedicados a Solano López dice " Era un hombre que bajaba y un divino que ascendía”(Ramos Giménez, 1936). A esto le sigue un artículo de Manuel Domínguez, sobre el juramento del héroe, luego continua con un extracto del texto del diplomático norteamericano Charles Washburn, que se refería a Solano López. Le sigue el artículo más extenso incluido en la obra, de la autoría de Natalicio González -otro de los referentes del nacionalismo 
paraguayo- que estaba dedicado al político uruguayo Luis Alberto de Herrera, titulado Solano López.

Luego el compilador procede a transcribir los discursos dados en el acto inaugural del Panteón siendo el primero el de Stefanich, quien hizo uso de la palabra en nombre del gobierno. Luego sigue el artículo del intendente municipal de Asunción, don Felipe Molas López. A continuación se encuentra una poesía de Marcelino Machuca Martínez, que se titula la Vuelta del Mariscal, para continuar con un artículo publicado en la prensa por Juan E. O’Leary, quien es titulado profesor de patriotismo, una poesía de Jorge Báez titulada El Panteón Nacional.

Se incluyó también una carta de Solano López a su hijo Emiliano fechada en el campamento de Azcurra el 22 de junio de 1869. También incluyó unos versos de Ortiz Guerrero, quien no sólo era compueblano de Ramos Giménez sino que incluso fue su compañero de escuela en Villarrica. Luego se incluye la intimación que le hicieron los aliados a Francisco Solano López en diciembre de1868 y la respuesta que él mismo les dio rechazando rendirse.

Finaliza el álbum con una serie de extractos de versiones sobre su muerte, acompañada en un recuadro de la poesía de Francisco Ortiz Méndez, la resolución del Congreso de Colombia y unas consideraciones breves de Guido Spano sobre López. En la última página se coloca un extracto de la obra de O’Leary sobre la mediación paraguaya encabezada por Solano López en el proceso de unificación de la República Argentina en 1859, y en el espacio inferior derecho en un apartado la poesía Cerro Corá de Félix Fernández.

\begin{tabular}{cc} 
Tipo de Texto & Cantidad \\
\hline Documentos Históricos & 2 \\
\hline Documentos Oficiales & 2 \\
\hline Texto Periodístico & 1 \\
\hline Discursos & 2 \\
\hline Artículos Históricos & 5 \\
\hline Testimonios & 2 \\
\hline Poéticos & 6
\end{tabular}

Como se pude observar de la anterior mención del contenido de la obra analizada se puede vislumbrar en ella tres partes, muy difusas entre sí pero que con atención se pueden distinguir. La primera es el reconocimiento a las autoridades que procedieron a la consagración de Solano López tanto en el aspecto documental como en la realidad con la inauguración del panteón y declarándolo prócer benemérito del Paraguay, y que además aprobaron los fondos para la impresión del álbum. Este parte 
concluye con la transcripción del decreto del 1 de marzo de 1936, por el cual "quedan cancelados para siempre de los archivos nacionales, reputándoselos como no existentes, todos los decretos-libelos dictados contra el Mariscal Presidente de la República, don Francisco Solano López por los primeros gobiernos establecidos en la república a raíz de la conclusión de la guerra de 1865" (Ramos Giménez, 1936).

La segunda parte es la acumulación tanto de textos de carácter histórico como poético que fueron producidos durante el período reivindicatorio, siendo el primero de ellos el de Manuel Domínguez, destacado jurista e intelectual paraguayo que integró la Generación del 900, y uno de los principales impulsores del nacionalismo paraguayo en el siglo XX. Este segundo apartado es completado con un artículo del propio canciller Juan Stefanich y de Natalicio González, uno de los principales referentes del nacionalismo en el siglo XX en Paraguay. En este sentido cabe señalar que no es accidental que el artículo más extenso haya sido de Natalicio González, quien al igual que Ramos Giménez había nacido en Villarrica y militaba en el Partido Colorado (ABC Color, 1985).

La tercera y última etapa del álbum se hace referencia a la consagración, los textos buscan registrar tanto el acto realizado el 12 de octubre cuando se inauguró el Panteón Nacional y se introdujeron los restos de Solano López y del soldado desconocido del Chaco, mediante la inclusión de los discursos oficiales, así como los versos de poetas contemporáneos que manifestaban su sentimiento ante dicho acto, intercalando los mismos con documentos históricos resultado en dos ocasiones de la pluma de Solano López, y dejando en claro los testimonios sobre su muerte, siendo dos de dichos textos extractos de la obra de Juan E. O'Leary, a quien se refieren en el álbum como nuestro profesor de patriotismo y en otro apartado como el apóstol de la nacionalidad (Ramos Giménez, 1936).

Otro aspecto destacable de la obra es la calidad gráfica de las imágenes que componen el álbum, en el cual como es lógico predominan varias imágenes de Solano López ya sean reproducciones de pinturas, grabados o daguerrotipos y fotografías del mismo. Complementadas con registros gráficos de la expedición que fue en busca de sus restos o de la capilla ardiente en el Palacio de López el 11 de octubre de 1936.

\section{Consideraciones finales}

El Álbum Apoteosis tiene un particular interés no sólo por ser una rareza bibliográfica, sino porque es el testimonio bibliográfico y documental que registra de una manera unificada el proceso de reivindicación y consagración de Solano López, como principal referente del Panteón Cívico de los paraguayos durante todo lo que resta del siglo XX, e incluso hasta la actualidad.

Es el documento que registra ese momento final en que concluye la reivindicación de la heroicidad de Solano López que comenzó en la famosa polémica de 1902 y que a su vez compila documentos y fotografías del inicio de la etapa consagratoria de Francisco Solano López como la figura histórica más alta y más completa de la nación paraguaya. 
Leopoldo Ramos Giménez al plantear la confección de dicha obra posiblemente tenía el propósito de dejar un testimonio escrito de un acontecimiento que los lopistas aguardaron durante varias décadas, acontecimiento por el cual lucharon en todos los frentes, desde la cátedra hasta en las calles, desde la prensa periódica hasta en las alocuciones radiales, buscando redimir a Francisco Solano López, quien para el estado paraguayo era oficialmente hasta 1936 "enemigo del género humano".

El esfuerzo editorial de Ramos Giménez con apoyo de fondos públicos, tuvo por resultado una obra elegante finamente impresa y cuidada que obviamente no pretendía ser una obra de gran difusión sino muy por el contrario ser ese registro elegante de un acto de "gran justicia histórica". Ese acto de reparación histórica frente a la historia oficial establecida luego de finalizada la Guerra contra la Triple Alianza, se convirtió en el período de la postguerra del Chaco en la historia oficial que tuvo su influencia incuestionable hasta fines del siglo XX. En dicha versión histórica no cabía ningún tipo de cuestionamiento a la figura, las acciones y decisiones de Solano López, debido a los usos políticos que los diferentes gobiernos hicieron de su figura histórica devenida en la de héroe máximo de la nacionalidad paraguaya.

\section{Referencias bibliográficas}

ABC Color. 1985. Entrevista a Leopoldo Ramos Giménez. Asunción.

Arce Farina, J. 2013. La Revolución de 1936, Asunción, El Lector.

Archivo del Liberalismo.1988.El Mariscal López. Una sesión histórica en la Cámara de Diputados. Asunción. Archivo del Liberalismo.

Benítez, L. G. 1986.Breve Historia de Grandes hombres, Asunción, Edición del Autor. Brezzo, L. 2009. “¡La gran polémica continúa! “. En: Nuevo Mundo Mundos Nuevos, Coloquios, 2009, [En línea], Puesto en línea el 13 enero 2009. URL: http:// nuevomundo.revues.org/48832. Consultado el 1 de junio de 2015.

Brezzo, L. 2010. "Reparar la Nación. Discursos históricos y responsabilidades nacionalistas en Paraguay". En: Historia Mexicana, vol. 60, nro. 1 (237), pp. 197-242.

Brezzo, L. 2011. Juan E. O'Leary, Asunción, El Lector.

Caballero Campos, Herib. 2012. ¿Cómo honrar a los héroes? La polémica en torno al Monumento a los Héroes de Asunción inaugurado en 1922”, En: Revista Paraguaya de Sociología,vol. 141, p. 93-111.

Caballero Campos, H. 2013. "Consideraciones sobre lo heroico y el establecimiento del Día de los Héroes en el Paraguay (1869-1936)”. En: Sergio Cáceres Mercado y Miguel Zarza (Org.). Identidad e Historia. Pensamientos del Bicentenario, Asunción, Centro de Investigaciones en Filosofía y Ciencias Humanas.

Caballero Campos, H. 2014. "En búsqueda de un Héroe: la construcción de la Figura Heroica del General José E. Díaz. Paraguay 1867-1906” En: Temas Americanistas, vol. 32, p. 22-44. 
Capdevila, L. 2010. "La sombra de las víctimas oscurece el busto de los Héroes, Historia del Tiempo Presente y Construcción Democrática (América Latina/Europa)”. En: Diálogos, vol. 14. 111-129.

Capdevila, L. 2010. Una guerra Total: Paraguay, 1864-1870. Ensayo de Historia Presente, Asunción/Buenos Aires, CEADUC/SB Ediciones.

Céspedes Ruffinelli, R. 2014. "Guerreros, estado y "progreso" en billetes del stronismo (1954-1989)”. En: Nuevo Mundo Mundos Nuevos, Coloquios, 2009, [En línea], Puesto en línea el 3 de diciembre de 2014. URL:http://nuevomundo.revues. org/67493. Consultado el 1 de junio de 2015.

Centurión, C. R. 1951. Historia de las Letras Paraguayas, Volumen III, Buenos Aires, Editorial Ayacuho.

González González, E. 2011.El gobierno de 1936 y su proyecto de Identidad Nacional, Asunción, El Lector.

Gómez Florentín, C. 2011. Higinio Morínigo. Asunción. El Lector.

El Diario. 1936. Asunción.

La Regeneración. 1869. Asunción.

Le Goff. 2009. El orden de la Memoria. Madrid, Paidos.

Makaran, G. 2014. Paraguay: El Nacionalismo y sus mitos, México, Centro de Investigaciones sobre América Latina y el Caribe. UNAM.

Mendiguren Sorazabal, J. 2001. La Década Infame. Testimonios y Vivencias 19371947, Asunción, Editorial Arandura.

Ramos Giménez, L. 1936. Apoteosis. Asunción. Compañía Editora Nacional.

Registro Oficial de la República del Paraguay.1870. Asunción.

Registro Oficial de la República del Paraguay.1871. Asunción.

Registro Oficial de la República del Paraguay.1936. Asunción, Imprenta Nacional.

Sansón Corbo, T. 2012. "Los prenovecentistas. Juan Silvano Godoy y José Segundo Decoud: discursos históricos en el Paraguay posbélico". En: Liliana Brezzo y Ma. Gabriela Micheletti (Comp.), Actas de la IV Jornada de avances de investigación en Historia Argentina: fuentes, métodos y problemas, Rosario, Pontificia Universidad Católica de Argentina - Instituto de Estudios Históricos, Económicos, Sociales e Internacionales (IDEHESI-CONICET).

Stefanich, J.1920. Alberdi, La Argentina y El Paraguay. Asunción.

Stefanich, J. 1929. Nacionalismo, Asunción.

Stefanich, J. 1945. La Restauración Histórica del Paraguay, Buenos Aires, Editorial El Mundo Nuevo. 
